\title{
Análisis de precio spot del acero en México: Caso de las importaciones Chinas en territorio nacional (Analysis of spot price of steel in Mexico: Case of the chinese imports in national territory)
}

\section{' Diego Enrique Caltzoncit Hernández ii Jesús Gerardo Cruz Álvarez}

\begin{abstract}
At the beginning of 2011, imports of Chinese steel in Mexico began to rise in a disproportionate way, because of the Asian region started a generating an overproduction of low-cost steel. This has led to the steel industry in Mexico reaches a break point in their prices. Derived from the express request of the Mexican steelmakers to the Government for install more requirements and taxes on imports from China, apparently volumes have begun to decline according to reports from CANACERO (it's acronym in Spanish, National Chamber of Iron and Steel Industry ) in 2016. With this information will proceeds to analysis the behavior of spot price of steel in Mexico for the next years.
\end{abstract}

Key words: china imports, chinese steel, spot steel price, steel Mexico.

JEL: G1, N6, F3.

Resumen. A principios del año 2011, las importaciones de acero chino en México empezaron a aumentar de manera desproporcionada a causa de que esta región asiática comenzó una sobreproducción de acero de bajo costo. Esto ha llevado a la industria del acero en México a un punto de quiebre en sus precios. Derivado de la petición expresa de las siderúrgicas mexicanas al gobierno para instalar más requisitos y aranceles sobre las importaciones procedentes de China, al parecer, los volúmenes han comenzado a disminuir según los informes de la CANACERO (por sus siglas en español, Cámara Nacional de la Industria del Hierro y del Acero) en 2016. Con esta información se procede al análisis del comportamiento del precio spot del acero en México en los siguientes años.

Palabras clave: acero chino, acero México, importaciones chinas, precio spot acero.

\footnotetext{
' UANL, Ciudad Universitaria, Av. Universidad s/n C.P. 66451, San Nicolás de los Garza, Nuevo León, México. i UANL, Ciudad Universitaria, Av. Universidad s/n C.P. 66451, San Nicolás de los Garza, Nuevo León, México. Correo: diegoehdz@hotmail.com
} 


\section{Introducción}

La industria siderúrgica forma parte del sector de los combustibles y minerales; según el último estadístico de la OMC (Organización Mundial del Comercio, julio 2016), ocupa el segundo lugar a nivel mundial en exportación, además de que dicha industria es una las más importantes en proveer insumos para las industrias del ramo automotriz, de la construcción, electrodomésticos y maquinaria pesada, entre otras. Según información del Banco de México, en el 2015 el comercio siderúrgico en el mundo representó el $2.7 \%$ del comercio total. De acuerdo a información recabada de la CANACERO, en 2015, México se encontró dentro de los primeros 15 países con mayor producción de acero, véase Tabla 1.

Tabla 1. Países con mayor producción de acero en 2015

\begin{tabular}{lll}
\hline Posición & Países & Producción \\
\hline 1 & China & 803.8 \\
2 & Japón & 105.2 \\
3 & India & 89.6 \\
4 & Estados Unidos & 78.8 \\
5 & Rusia & 70.9 \\
6 & Corea del Sur & 69.7 \\
7 & Alemania & 42.7 \\
8 & Brasil & 32.7 \\
9 & Turquía & 31.5 \\
10 & Ucrania & 23 \\
11 & Italia & 22 \\
12 & Taiwán & 21.4 \\
13 & México & 18.2 \\
14 & Irán & 16.1 \\
15 & Francia & 15 \\
16 & Otros & 181 \\
\hline
\end{tabular}

Fuente: CANACERO con datos de World Steel Association (2015)

Sin embargo México también está dentro de los 10 mayores importadores de acero del mundo, en el 2014 importó 12.4 millones de toneladas y en el 2015 13.7 millones de toneladas de acero. Las exportaciones en el 2014 fueron de 5.8 millones de toneladas y de 4.3 millones de toneladas en 2015. Véase Figura 1. 
Figura 1. Balanza comercial del acero en México
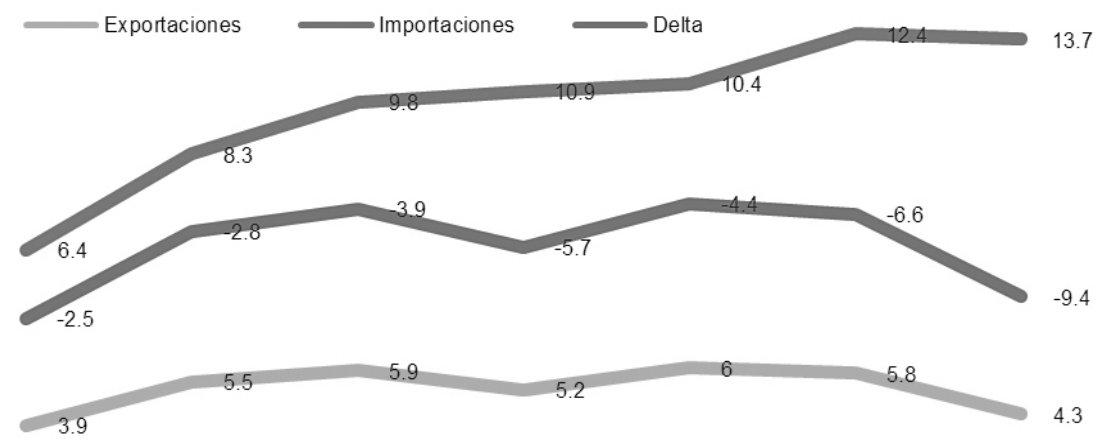

Fuente: Elaboración propia, adaptado de CANACERO

En México, empresas como Villacero, AHMSA (Altos Hornos de México, Sociedad Anónima), DeAcero, así como empresas de inversión extranjera como ArcelorMittal o Ternium, generan una masiva fuente de empleos para los mexicanos. Aunque derivado del efecto China, entre 2010 y 2015 se perdieron 24 mil empleos. Véase Figura 2.

Figura 2. Número de personas empleadas en la industria del acero

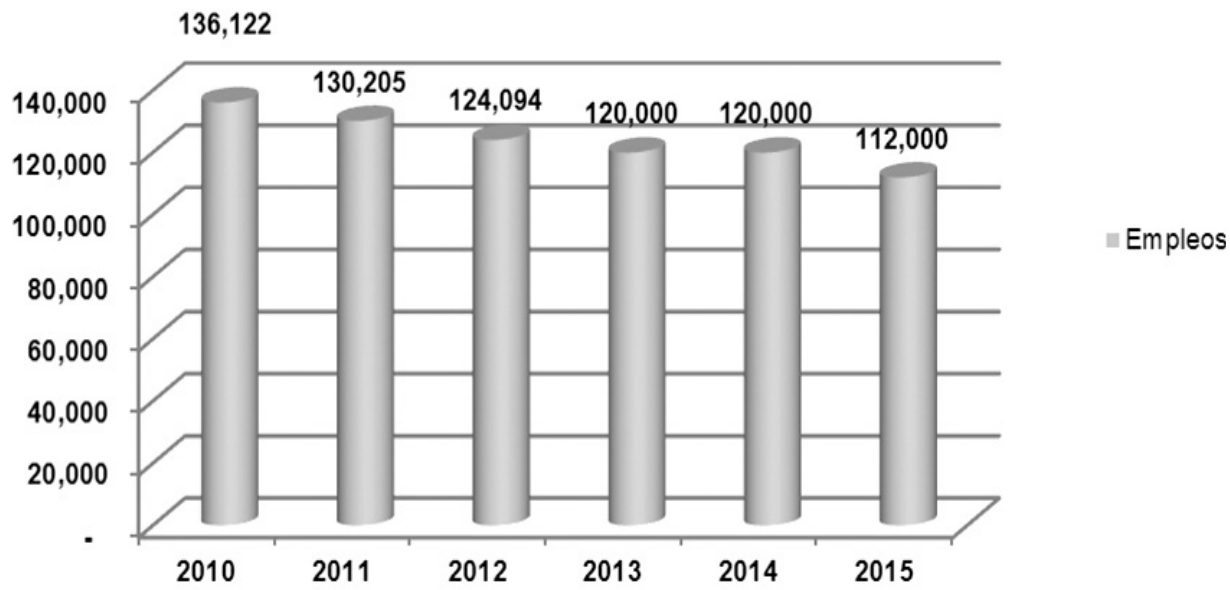

Fuente: Elaboración propia, adaptado de CANACERO 
El denominado "Dragón Chino" (Arteaga, 2015), "El síndrome China" o simplemente el "efecto China" ha venido a cambiar la situación actual del mercado mexicano. Dicho efecto se puede describir como la sobreproducción acelerada de acero en aquel país asiático a un costo muy bajo. México ocupa el primer lugar como receptor de las importaciones provenientes de la nación asiática en Latinoamérica.

Este artículo tiene por objeto recabar la información generada en los años 2011 al 2016 en este tema y, con base en dicha información, contar con una visión más amplia y clara de hacia dónde se perfilan los precios en el mercado y con ello realizar un pronóstico lo más exacto y certero posible acerca de cuál será la tendencia en los precios del acero en México; se espera que este análisis sirva de herramienta para una mejor valuación de costos en las empresas o negocios del ramo acerero, así como una guía para aquellos que se dedican a la compra y venta de metales, o sus derivados, y con ello se logre una exitosa planeación de materiales en sus cadenas de suministros e inventarios. A continuación se muestran en la Figura 3 las variables independientes o explicativas que se ven afectadas por la variable dependiente, China.

Figura 3. Mapa conceptual del acero Chino en el mundo

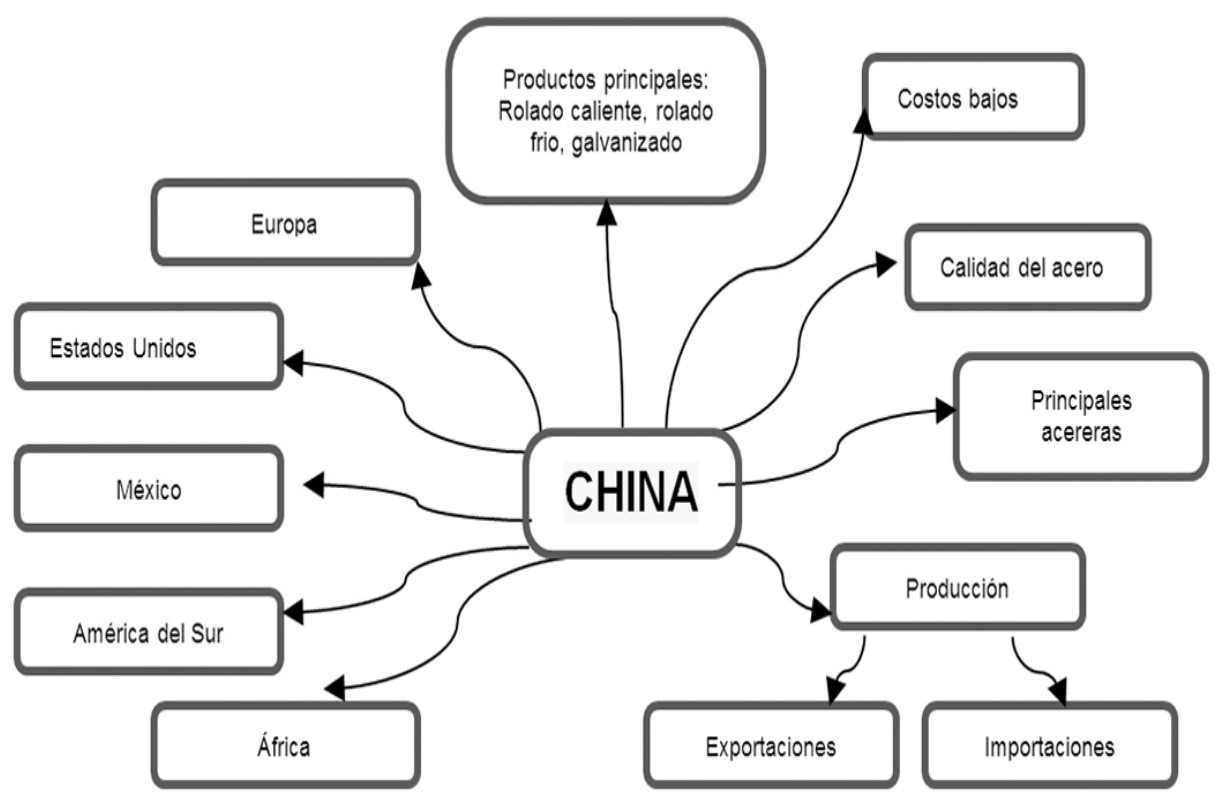




\section{Metodología}

este artículo de investigación se consideran informaciones referentes del periodo 2011 a mediados de 2016 y se analizan diversas fuentes oficiales y artículos publicados en diversas plataformas de investigación como Google Scholar, ISI web of knowledge, Redalyc y bases de datos disponibles en la UANL (Universidad Autónoma de Nuevo León); con estas fuentes se procedió a construir un cuerpo de conocimientos que se inició con un histórico de la industria acerera mexicana y su afectación en dicho periodo, para así estimar los precios futuros del acero en territorio nacional.

Las variables consideradas en este estudio son el costo del acero y la cantidad de toneladas exportadas e importadas en México, con base en esta información se elabora un análisis con la finalidad de obtener un pronóstico lo más confiable y exacto posible. Es importante señalar que se consideraron también las nuevas leyes arancelarias aplicadas por el gobierno mexicano a finales del año 2015.

\section{Revisión literaria}

\section{Factores que propiciaron el efecto China}

China es el principal mercado del acero, así lo demuestran los informes estadísticos de la WSA (World Steel Association). La Asociación Mundial del Acero recopila las estadísticas del sector e indica que China generó un récord de producción de 822.8 millones de toneladas de acero en 2014 y de 803.8 millones de toneladas en 2015 ocupando el primer lugar en ambos años. La Asociación Mundial del Acero basa sus cálculos de producción en cifras proporcionadas por la oficina nacional de estadísticas de China y la Asociación China del Hierro y del Acero; así lo determina con cada país que se encuentra registrado en dicha asociación.

Las cifras indican que China se ha estado concentrando en producir acero y asegurando compradores. Podría haber más acero almacenado en China del que otros productores desconocen. "Si la economía china se lentifica, gran parte de ese acero sería exportado, lo que podría hacer que los precios caigan" (Matthews, 2011). No estaba equivocado. A continuación las Figuras 4 y 5 muestran la producción y distribución de acero en el 2005 y el 2015: 
Figura 4. Producción de acero y distribución en 2005. Distribución geográfica 2005 / Total: 1,149 millones de toneladas Adaptado de la Asociación Mundial del Acero

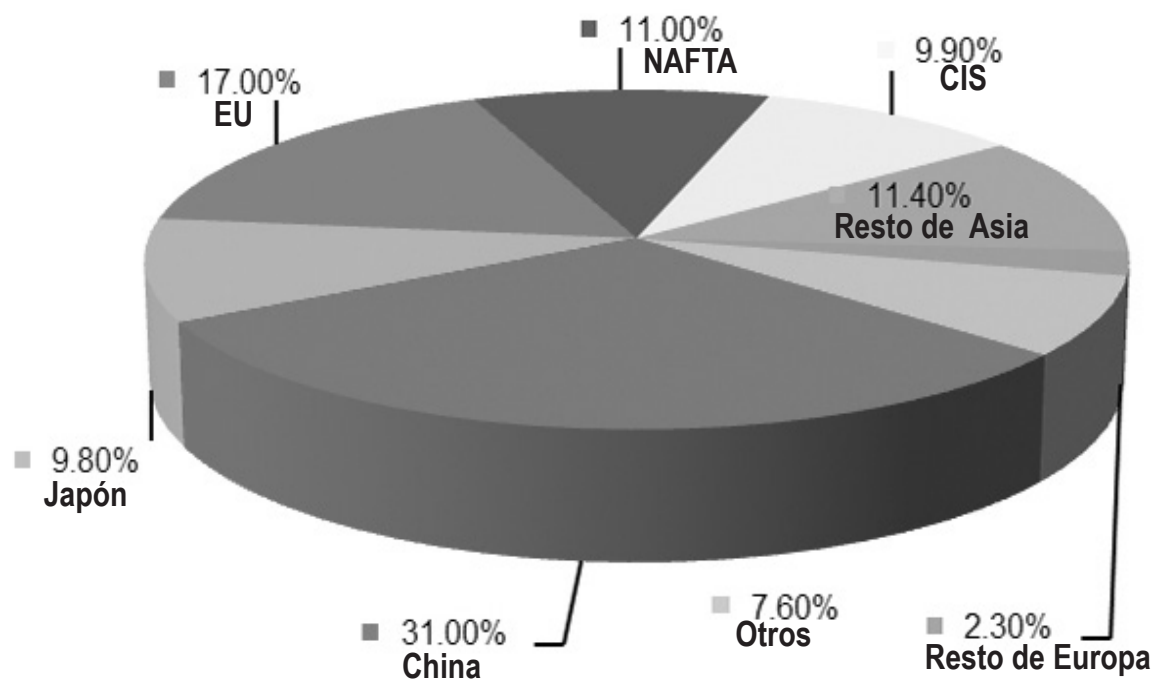

Fuente: Elaboración propia, con información de la WSA

Figura 5. Producción de acero y distribución en 2015. Distribución geográfica 2015 / Total: 1,621 millones de toneladas.

Adaptado de la Asociación Mundial del Acero

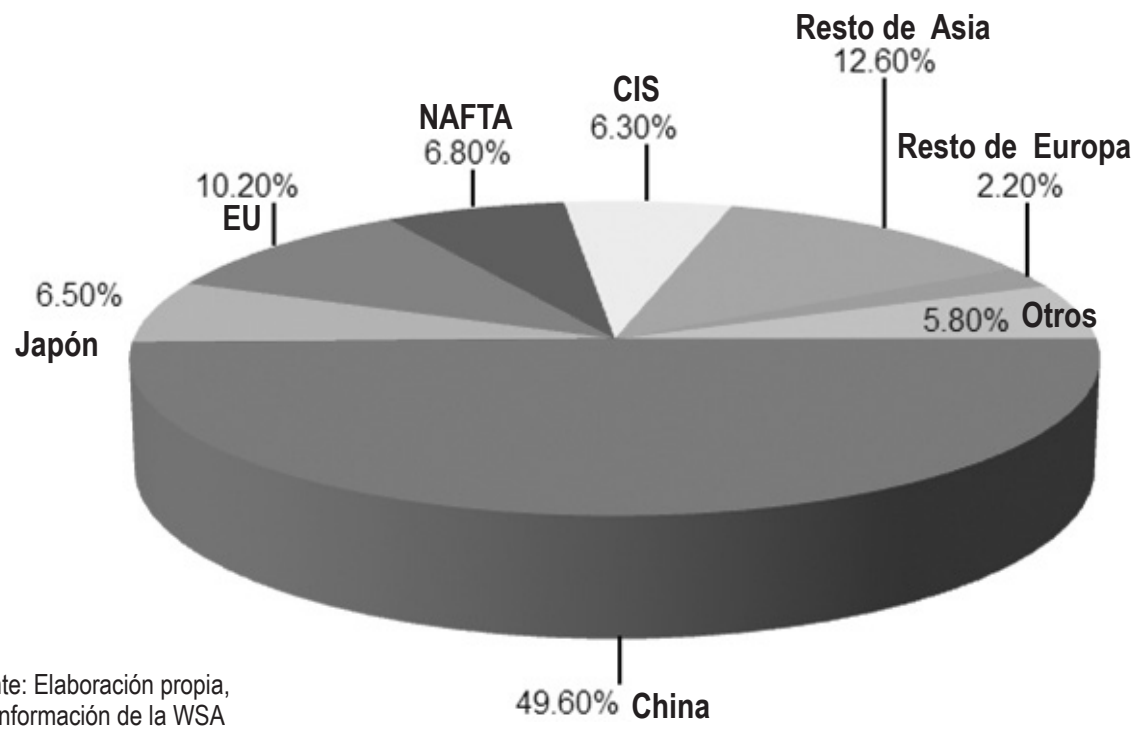


En la última década China se ha convertido en el polo dinámico de la economía mundial, ha devenido en ser el primer exportador de bienes, el quinto de servicios y el primer consumidor mundial de energía y automóviles. Si en 1990 China llegaba a $5 \%$ del consumo mundial de productos básicos, hoy es el principal consumidor de aluminio, cobre, estaño, soja y zinc, y el segundo consumidor de azúcar (Sevares, 2011). Como consecuencia de esta expansión, la nación asiática aumentó su posición como socio comercial en todas las economías del mundo, incluyendo las latinoamericanas.

El aumento de la demanda china contribuyó, a su vez, a la variación de los precios de los commodities y modificó la evolución del sistema de precios relativos del mercado mundial. Las grandes acereras chinas que conforman consorcios estatales que compiten sin pagar el costo internacional de energía y sin cumplir algunas leyes, mismas que sí enfrentan sus competidores, son un gigantesco monstruo que invade la industria siderúrgica mundial (Manrique, 2004). De acuerdo a la WSA, las dos más grandes acereras chinas, Hebel Iron \& Steel Group y Baosteel Group, están en proceso de fusión.

Las acereras chinas producen, en conjunto, la mitad del acero mundial: sus 600 millones de toneladas anuales inundan los mercados con prácticas desleales de comercio al operar con subsidios de su gobierno. $Y$ frente a una demanda aparente mundial de mil 600 millones de toneladas, la OCDE (Organización para la Cooperación y el Desarrollo Económico) estima que el exceso de capacidad global de acero alcanza las 700 millones de toneladas, de las cuales 400 millones corresponden a China. En la Tabla 2 se enlista el Top 10 de empresas productoras de acero en el 2015.

Tabla 2. Top 10 de empresas productoras de acero en el mundo en 2015

\begin{tabular}{llll}
\hline Lugar & Empresa & Producción & País de origen \\
\hline 1 & Arcelor Mittal & 96.1 & India \\
2 & Nippon Steel & 50.1 & Japón \\
3 & Hebei Steel & 47.1 & China \\
4 & Baosteel & 43.3 & China \\
5 & Wuhan Steel & 43.1 & China \\
6 & Posco & 38.4 & Corea \\
7 & Shagang & 35.3 & China \\
8 & Anseel & 34.3 & China \\
9 & JFE & 31.2 & Japón \\
10 & Shougang & 30.8 & China \\
\hline
\end{tabular}

Millones de toneladas por año. Fuente: Elaboración propia con información de la WSA (2015) 


\section{Importancia de la industria siderúrgica en México.}

Acorde a los datos obtenidos por la WSA, la producción de acero en la República Mexicana en el año 2014 fue de 18.9 millones de toneladas y de 18.2 millones en el año 2015. La producción de acero líquido se concentra en 11 estados del país, entre los que se encuentran: Coahuila, Michoacán, Nuevo León, Guanajuato y Veracruz. Aviones, coches, tubos y utensilios de cocina son algunos de los productos que forja la industria del acero en el país.

En los últimos meses, Toyota, BMW, KIA Motors y otras automotrices han anunciado inversiones en sus plantas que detonarán el consumo de acero en el país, un negocio que despierta el interés de los empresarios mexicanos. Ciudades como Puebla, Nuevo León y Guanajuato se encuentran beneficiadas con este auge en el sector automotriz.

En México, la industria siderúrgica despuntó a principios del siglo XX durante el porfiriato (época donde el país estaba capitalizado por la inversión extranjera) y en ese tiempo era de gran importancia para satisfacer la demanda de la construcción, del ferrocarril y de las nuevas industrias que se iban creando (Barragán, 2015).

A mediados del siglo XX la industria siderúrgica se nacionalizó, y de esta forma el Estado tuvo a su disposición un sector básico para las grandes inversiones que hacía en la construcción de edificios, carreteras, puentes, presas, servicios públicos y transportes, entre otros. Y entre más crecía la inversión del estado, mayor era la demanda de acero; por lo que el Estado tuvo expectativas de que fuera a seguir creciendo la demanda de acero y lo impulso a que en 1972 se realizara una fuerte inversión para la apertura de SICARTSA, (acrónimo de Siderúrgica Lázaro Cárdenas Las Truchas, S.A.) la primera y única empresa siderúrgica creada por el Estado (Barragán, 2015).

A finales del año 2006, SICARTSA fue vendida al gigante acerero Arcelor Mittal en más de 1,400 millones de dólares. Y es la principal productora de varilla y alambrón de México, tiene reservas probadas de hierro para 50 años, realiza operaciones por 5.5 millones de toneladas al año y posee minas, plantas de concentración y tratamiento del metal, hornos, convertidores, molinos, subestaciones e infraestructura de las más grandes del planeta.

La importancia del sector siderúrgico en México dentro de la actividad económica refleja en 2013 una participación de $2.2 \%$ respecto del PIB Nacional. La siderurgia contribuye con $6.4 \%$ del PIB Industrial y, en lo que se refiere a la 
Industria Manufacturera, en 2008 alcanzó su nivel más alto con $14.9 \%$. En 2013, el sector presentó un valor de 346 mil 797 millones de pesos (12.6\% del PIB manufacturero).

En el mundo, la industria acerera es una de las más importantes por ser proveedora de materia prima para las industrias del ramo automotriz, construcción, alimentos, electrodomésticos, maquinaria pesada, entre otras. Estas empresas son una gran fuente de riqueza, cuya derrama económica beneficia a miles de familias alrededor del mundo (Nahuat, 2016).

Grandes empresas han sido creadas a lo largo del tiempo en México, AHMSA (Altos Hornos de México Sociedad Anónima), HYLSA (Hojalata y Lámina Sociedad Anónima), VILLACERO, por mencionar algunas. El gran incremento de productos chinos a bajo precio está amenazando el futuro de la industria siderúrgica y metalmecánica nacional, que se encuentra en total desventaja para competir en un mercado de alta demanda.

Es por ello que las acereras mexicanas buscan siempre contar con lo último en tecnología en sus plantas y con ello contar con mejores procesos de fabricación, así como tener una especialización en los grados de acero que genere un negocio más rentable y, a la vez, disminuir la contaminación en pro del medio ambiente.

En los últimos meses, AHMSA y TERNIUM le están apostando a nuevas tecnologías, por ejemplo AHMSA invirtió 140 millones de dólares en una planta de Normalizado de placa, la cual está enfocada en la fabricación de aceros especiales para la industria automotriz y la energética. Por su parte TERNIUM anunció que duplicará su producción de aceros especiales para el 2019, así como duplicar su producción de la planta Tenigal, en Pesquería, Nuevo León.

$A$ un año de que los industriales acereros anunciaran que estaban en crisis, por lo que tendrían que cerrar plantas e iniciar despidos masivos, el Secretario de Economía, Ildefonso Guajardo Villarreal, recibió a los agremiados de la CANACERO, quienes exigieron acciones inmediatas contra la "competencia desleal".

Acusaron que el acero chino provocó un quebranto de escala mundial en el sector, pero la diferencia es que otros países lanzaron programas de emergencia para proteger sus industrias y México no (García, 2015). A raíz de este encuentro y al incremento de las presiones del sector siderúrgico, el gobierno decidió agregar aranceles o cuotas antidumping como una contraofensiva. 
Tal es el caso de Brasil, que desde hace casi 2 años sancionó a todos los productos siderúrgicos de China con aranceles del 8 a 14 por ciento. Fue a finales del 2015 cuando el gobierno mexicano comprendió la problemática que representaba la sobreproducción de acero en China. En octubre de ese año, la Secretaría de Economía incrementó los aranceles temporales al acero chino y de otras naciones con las que México no tiene un tratado de libre comercio. Dichos aranceles se elevaron a una tasa del 15 por ciento en contra de cinco familias de productos: planchón, placa, lámina rolada en caliente, lámina rolada en frío y alambrón.

\section{Precios del acero en México}

Para esta investigación se recurrió a recolectar los precios más exactos, válidos y confiables, es por ello que se consulta a una de las fuentes de información de índices de precios más reconocida a nivel global: CRU, principal autoridad para el mundo de los metales, la minería, la energía y cables, fertilizantes y productos químicos. CRU fue establecida en 1969 y solía tener su sede en Londres, ahora tiene oficinas en Beijing, Santiago, Mumbai, Sídney, Río de Janeiro, Washington, Seattle, Filadelfia, Raleigh, Rhode Island y Pittsburgh.

El nombre de la compañía significa Commodities Research Unit. Entre sus múltiples actividades se encuentran el análisis, pronóstico y exactitud en los precios a lo largo de los años, con coberturas en los mercados que van desde el acero hasta los metales base. Es a través de ella que a continuación se muestra la información recabada en cuanto a los precios del acero en México durante el periodo del año 2011 a septiembre de 2016, véase Tabla 3 y Figura 6: 
Tabla 3. Histórico de precios del acero en México

\begin{tabular}{lllll}
\hline Año & Mes & Rolado caliente & Rolado frío & Galvanizado \\
\hline 2011 & Ene - Mar & 843.77 & 962.93 & $1,030.05$ \\
2011 & Abr - Jun & 877.07 & 996.86 & $1,054.18$ \\
2011 & Jul - Sep & 896.18 & $1,009.35$ & $1,080.26$ \\
2011 & Oct - Dic & 758.02 & 882.58 & 955.70 \\
2012 & Ene - Mar & 724.95 & 846.57 & 922.63 \\
2012 & Abr - Jun & 794.40 & 908.67 & 978.85 \\
2012 & Jul - Sep & 727.53 & 845.11 & 907.94 \\
2012 & Oct - Dic & 689.68 & 810.93 & 877.44 \\
2013 & Ene - Mar & 683.43 & 803.95 & 858.70 \\
2013 & Abr - Jun & 679.76 & 799.18 & 861.64 \\
2013 & Jul - Sep & 652.94 & 773.45 & 834.82 \\
2013 & Oct - Dic & 709.52 & 829.31 & 890.30 \\
2014 & Ene - Mar & 726.42 & 849.88 & 912.35 \\
2014 & Abr - Jun & 721.65 & 856.13 & 910.88 \\
2014 & Jul - Sep & 739.65 & 739.65 & 940.27 \\
2014 & Oct - Dic & 735.98 & 875.60 & 938.80 \\
2015 & Ene - Mar & 699.23 & 838.49 & 913.82 \\
2015 & Abr - Jun & 591.21 & 742.96 & 816.08 \\
2015 & Jul - Sep & 500.08 & 633.46 & 719.44 \\
2015 & Oct - Dic & 505.96 & 648.16 & 720.54 \\
2016 & Ene - Mar & 426.59 & 568.06 & 626.85 \\
2016 & Abr - Jun & 439.09 & 608.11 & 672.41 \\
2016 & Jul - Sep & 619.13 & 825.26 & 885.16 \\
\hline
\end{tabular}

Fuente: Elaboración propia, precios promedio en dólares americanos. Fuente: CRU (2016) 
Figura 6. Histórico de los precios del acero en México

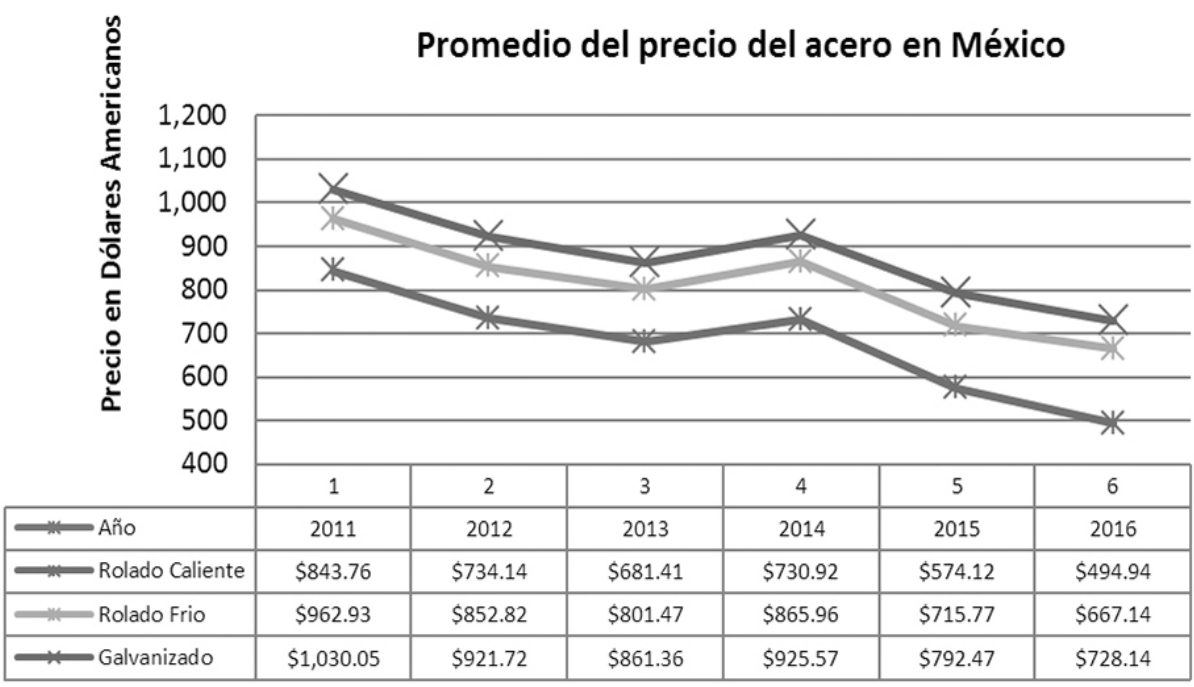

Fuente: Elaboración propia, precios promedio en dólares americanos. Fuente: CRU (2016)

A continuación se muestra el modelo diseñado para la investigación referente a los precios spot del acero en México:

\begin{tabular}{|c|c|c|}
\hline Rigor metodológico & Justificación & Resultados esperados \\
\hline $\begin{array}{l}\text { Investigación } \\
\text { documental }\end{array}$ & $\begin{array}{l}\text { Revisión de los antecedentes } \\
\text { que han propiciado la baja en } \\
\text { los precios del acero en México }\end{array}$ & $\begin{array}{l}\text { Contar con una base sustentable } \\
\text { de los motivos que han generado la } \\
\text { caída en los precios en los últimos } \\
\text { años }\end{array}$ \\
\hline $\begin{array}{l}\text { Estadística } \\
\text { descriptiva }\end{array}$ & $\begin{array}{l}\text { Se consultan fuentes de infor- } \\
\text { mación primarias para la investi- } \\
\text { gación, como son: INEGI, WSA, } \\
\text { CRU. }\end{array}$ & $\begin{array}{l}\text { El obtener información real y con- } \\
\text { fiable beneficia para obtener nú- } \\
\text { meros más exactos para nuestras } \\
\text { proyecciones de precios futuros. }\end{array}$ \\
\hline $\begin{array}{l}\text { Análisis } \\
\text { de corte transversal }\end{array}$ & $\begin{array}{l}\text { Para facilitar el manejo de la in- } \\
\text { formación se tomará un periodo } \\
\text { definido del tiempo. }\end{array}$ & $\begin{array}{l}\text { Con base a la información recaba- } \\
\text { da en el periodo del } 2011 \text { al } 2016, \\
\text { se contempla la determinación para } \\
\text { los precios futuros en México. }\end{array}$ \\
\hline Experimen & $\begin{array}{l}\text { Se determinarán diferentes es- } \\
\text { cenarios de manera que poda- } \\
\text { mos simular posibles situacio- } \\
\text { nes en el mercado del acero. }\end{array}$ & $\begin{array}{l}\text { Agregando diversas variables in- } \\
\text { dependientes, podremos definir el } \\
\text { posible rumbo de los precios spot } \\
\text { del acero en México. }\end{array}$ \\
\hline
\end{tabular}




\section{Resultados}

Una vez que se ha recolectado la información, se procede a mostrar dos escenarios posibles que se pueden llegar a presentar en los próximos meses en el mercado del acero en México.

Cabe destacar que las variables consideradas para estos pronósticos de los precios spot del acero fueron las toneladas producidas en el país, las toneladas producidas por China y los nuevos aranceles que se están implementando por nuestro gobierno, entre otras.

A continuación se presenta el escenario 1 en la Figura 7, el promedio estimado de precios del acero en México para lo que resta del año 2016 y los próximos años.

Figura 7. Escenario 1: Pronóstico de los precios del acero en México

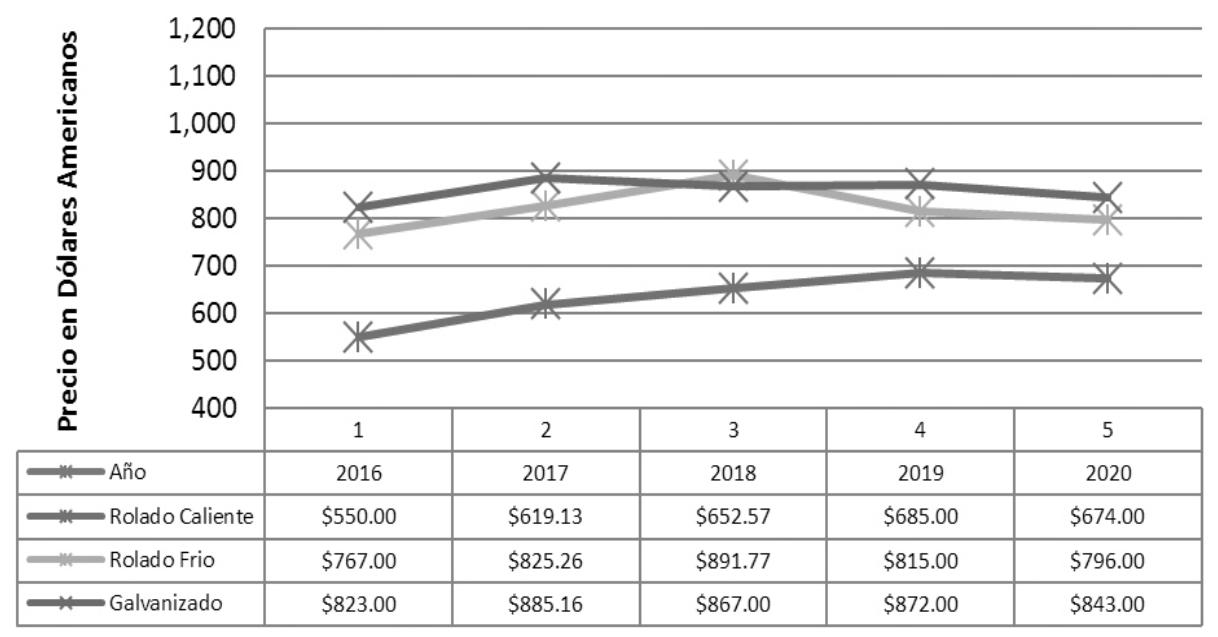

Fuente: Elaboración propia.

El cálculo de los precios para el cierre del año 2016 se basa en el promedio de los precios vigentes mostrados por el CRU al cierre del mes de septiembre, en el año 2017 se considera como adicional al precio promedio un incremento del $15 \%$ derivado de los impuestos arancelarios designados por el gobierno mexicano para combatir las masivas importaciones chinas.

Para el resto de los años se realizó un cálculo de precios promedios tomando como base la información de la Tabla 3 . Se considera que los precios irán 
al alza conforme se mantengan por lo menos en un $5 \%$ al $10 \%$ los impuestos arancelarios.

A medida que va avanzando el año, el gobierno de México se ha dado cuenta de la magnitud de su error al no haber instaurado los aranceles hace tiempo, sin embargo, con esta medida, los precios se han ido reponiendo, la sobreproducción del acero chino se ha detenido por el momento y cada vez más empresas internacionales instaladas en suelo mexicano están volteando a ver la calidad del acero mexicano, empresas del norte y centro del país están instalando plantas automotrices, lo cual traerá beneficios como más empleos, inversión en tecnologías y una derrama económica importante. Cabe señalar que aunque los precios no llegarían a los números de años anteriores, al menos los precios ya no estarían a la baja en México.

El otro escenario que se puede llegar a presentar en los precios spot del acero en México es uno no favorable, desalentador y pesimista. Hay ciertos factores que giran en torno a dicho escenario, entre los cuales destacan que si China obtiene ante la OMC (Organización Mundial del Comercio) la economía de libre mercado en diciembre próximo, el país asiático podría inundar al mundo con 700 millones de toneladas de acero.

Esto es derivado de que en dicho mes vence el plazo de 15 años que la OMC le otorgó al país asiático para modificar el control central que tiene el Estado sobre su economía, dentro del protocolo de Adhesión de China.

Así mismo la competencia desleal no solo proviene de China, países como Rusia y Ucrania están en la mira del gobierno mexicano por posibles prácticas desleales de tipo dumping.

Aunado a esto, las afectaciones del valor de la divisa nacional frente al dólar americano derivado de las pasadas elecciones presidenciales en el país de las barras y las estrellas son un factor adicional que puede llevar al valor del acero en México a precios nunca antes vistos.

En la Figura 8 de la siguiente página se muestra el escenario 2 del pronóstico de los precios del acero en México en caso de presentarse las variables dependientes antes mencionadas: 
Figura 8. Escenario 2. Pronóstico de los precios del acero en México

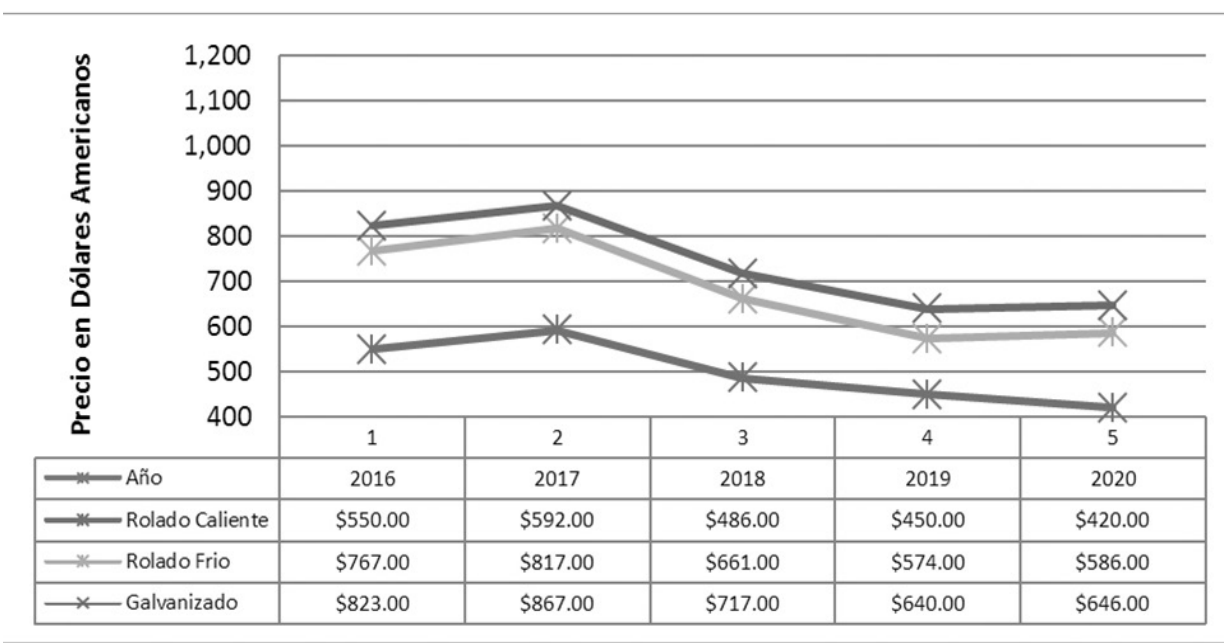

Fuente: Elaboración propia.

El cálculo de los precios para el cierre del año 2016 se basa en el promedio de los precios vigentes mostrados por el CRU al cierre del mes de septiembre, para los años posteriores se realizó un cálculo de precios promedios con base en el histórico de la base de datos de la Tabla 3. Este cálculo toma en consideración que el gobierno mexicano retire el arancel a las importaciones chinas, que es al momento de un $15 \%$ e incluye a las familias de productos rolado caliente, rolado frío y galvanizado.

\section{Discusión}

Podemos resumir que la sobreproducción en China en materia siderúrgica, aunada a un lento crecimiento de su economía, dio lugar a exportaciones masivas del país asiático en condiciones desleales bajo un escenario de apertura total en México. Esto fue lo que derivó que a finales del 2014 y durante el 2015 la industria siderúrgica nacional pasara por un periodo de crisis con paros en producción y recortes de personal importante. Pero a partir de octubre de 2015 se comenzó a combatir a esta situación a través de la aplicación de un arancel temporal por 6 meses a todo material de acero proveniente de aquella región asiática. Mismo que el gobierno mexicano decidiera renovar su vigencia por otros 6 meses en abril de 2016. 
A través de la información recabada durante el periodo del año 2011 a mediados del 2016, se puede visualizar la manera que el efecto China influyó en los precios spot del acero, registrándose una disminución que rebasa el $40 \%$ de su precio en el acero rolado caliente, de una baja del $30 \%$ en el acero rolado frio y una baja de $28 \%$ al acero galvanizado. El efecto colateral fue la reducción de fuentes de empleos en casi un $20 \%$ de la plantilla laboral, según datos de la CANACERO.

China se erige como el principal productor e importador de acero en el mundo en los últimos años, esta tendencia se ha visto reflejada más recientemente en el año 2014 y 2015 gracias a la información de la WSA. China produce alrededor de la mitad del acero en el mundo, al momento tiene una capacidad instalada no menor a 1,250 millones de toneladas anuales. Contar con un gran apoyo de su Estado ha sido uno de los factores principales de expansión, a su vez, el costo de la energía eléctrica es bajo en comparación con los países europeos. Hay ciertos factores que se dejan de lado al adquirir el acero Chino a bajo costo, destacan la calidad del producto, tiempos de traslado, volúmenes de pedidos, entre otros.

Con base en las acciones que se están realizado por parte del gobierno mexicano, como lo son los aranceles a todo material proveniente de China, aunado a la desaceleración paulatina de su producción y la inversión de nuevas tecnologías por parte de la siderurgia nacional, hace vislumbrar un repunte en los precios spot del acero mexicano, de manera paulatina se está comenzado a recuperar la economía y sus precios. Este es el primer escenario que se llega a mostrar en la investigación.

Sin embargo, está su contraparte, el cual es un panorama no favorable, ya que de seguir la sobreproducción del acero chino, y si se continúa con la depreciación del peso frente al dólar americano, o se llegasen a eliminar los aranceles o acabase la vigencia de estos, el precio spot del acero en México continuará decayendo hasta un punto de quiebre. Es un escenario pesimista, pero posible y verdadero. Queda en manos del gobierno y de los empresarios acereros el continuar con esta batalla o caer frente al denominado "Dragón Chino". 


\section{Referencias}

Arteaga, J. R. (2015). El dragón chino amenaza a la industria del acero en México. Sección Negocios, Revista Forbes, México.

Barragán, M. (2015). Ensayo la industria siderúrgica, un sector estratégico para la economía, en http://www.academia.edu/24828787/ensayo_la_industria_sider\%c3\%9argica_ un_sector_estrat\%c3\%89gico_para_la_econom\%c3\%8da

García, A. R. (2015). El gobierno de Peña Nieto, omiso ante la crisis acerera. Revista Proceso. en https://www.proceso.com.mx/409276/409276-el-gobierno-de-pena-nieto-omisoante-la-crisis-acerera.

Manrique, L. (2004). El "síndrome de China" se extiende por América Latina. Real Instituto Elcano de Estudios Internacionales y Estratégicos, (Economía Internacional), 1-7.

Matthews, R. G. (2011). China plantea una adivinanza sobre el acero. Agence FrancePresse, 3, 12-13.

Nahuat, J. J. (2016). Mercado global del acero: el reto de la internacionalización de la industria acerera mexicana global steel market: the challenge of internationalization of mexican steel industry. Revista Global de Negocios, 4(4), 83-94

Sevares, J. (2011). El ascenso de China: oportunidades y retos para América Latina. Nueva Sociedad, 1-15. 